\title{
Epilogue
}

\section{Corporate Cosmic Spirituality for Today}

\section{Executive Summary}

Every human being is spiritual and has spirituality, whether it is existential and subconscious or reflective and explicitly conscious. The existential subconscious level of spirituality informs and empowers our conscious decisions, choices, and actions. In this sense, spirituality is the continuous line of action that fashions our personal and collective human and cosmic identity. Despite our native spirituality that unites and harmonizes humanity, we also experience the fallen nature of the human heart and the resulting brokenness of human relations as the major cause of crises in our lives, families, corporations and nations, and now the life-threatening ecosystems that form our common planetary home. Hitherto, we have falsely presumed that the earth and the universe are for the use of mankind - an anthropocentric concept of ecology and sustainability. Hence, we are on the verge of destroying the planet. We need planetary ethics and cosmic spirituality to change our mind-set - from anthropocentricism to cosmocentricism and from being the conqueror of nature to being a caring partner of nature. This is the essence of corporate cosmic spirituality. Human spirituality in general and corporate executive spirituality in particular seem to be the best way to understand and offer a way out of the personal, communal, and planetary disorders of our age. This concluding note of this book is a summons to all corporate executives to rise to the call of cosmic spirituality.

\section{Introduction}

The central thesis of Laudato Si, an Encyclical on the Spirituality of Sustainability issued by Pope Francis on May 24, 2015, is that the fallen nature of the human heart and the resulting brokenness of human relations are the cause of the crises in our lives, families, nations, and now, the life-sustaining ecosystems that form our common home. The document focuses on the heart of man and the disorders of our age. Pope Francis stresses the link between human and environmental crises, which he says "are ultimately due to the same evil: the notion that there are no indisputable truths to guide our lives, and hence, human freedom is limitless." In other words, Laudato Si' follows the arc of salvation 
history to understand and offer a way out of the personal, communal, and planetary disorders of our age.

Today, many people do feel a deep sense of ecological commitment that has been awakened by observing how our planet is fragile and threatened. The effect of this observation of planetary fragility is not only a sentiment of responsibility but a call to act in a responsible way. In this transition from inner feeling to concrete ecological action, we need our rationality. We have to conceptualize our intuition, make a trade-off between different aims and allocate time and scarce means. But what is clear is that there is a spiritual sense of responsibility that precedes the stage of rational conceptualization and implementation.

\section{What is Corporate Spirituality?}

Spirituality cannot be captured in one standardized definition. Spirituality is a rich, intercultural, and multilayered concept. As a guideline, Zsolnai $(2015$, p. 4) proposes a working definition (developed by the European SPES Forum): spirituality is people's multiform search for the deep meaning of life that interconnects them to all living beings and to "God" or Ultimate Reality (European SPES Forum 2014).

"It is reasonable to think that every human being has a spirituality" (Haight, 1987, p. 21). According to Roger Haight (1987, p. 22), "the term spirituality can be understood on at least two levels, the one existential and the other reflective and explicitly conscious. On the first and the deepest level of action, spirituality is constituted by the conscious decisions and actions that make the person to be who he is or she is; spirituality is the continuous line of action that fashions a person's identity. On the second reflective level, spirituality refers to a theory or theoretical vision of human life in terms of the ideas, ideals, and ultimate values that should shape it. These two levels constantly interact in the thinking person."

Human spirituality is a phenomenon beyond legality, ethics, and morals; and beyond any ethical theory or paradigm. Spirituality is beyond any exercise, regime, program, regimen, project, or enterprise. It is something internal and intrinsic to humankind arising from being created in the "image and likeness of God." It is a gift from God by which we participate in the love, sanctity, and divinity of God. Spirituality is native to us, inborn in us, as also cultivated by wisdom and virtue, renunciation (tyaga) and service (seva), integrity (dharma), and holiness.

The central claim of The Spiritual Dimension of Business Ethics and Sustainability Management (Laszlo Zsolnai, ed., 2015) is that both business ethics and sustainability management require spirituality as a foundation. Without spiritually motivated actors, ethical business initiatives and proenvironmental activities can become ineffective and meaningless, and sometimes even counterproductive and destructive. That is, we need spirituality.

Spirituality is the science of the heart. When we learn to connect with it we will find that everything is there. Most amazingly, we find out that we are all 
connected to each other through our hearts. When we tune ourselves to the same frequency, we will be in the same wave length, same page, same cosmic space, and journey where we are all one. When we have less resistance in our hearts, we let go and become a part of that journey. Then, we become unified as one single entity, in one cosmic flow of love and forgiveness, harmony, and solidarity with nature.

\section{Corporate Ethics Is Not Enough}

Business ethicist Luk Bouckaert (2015, p. 20) argues that a more spiritual approach to business ethics is needed and that business ethics needs a spiritual foundation. The basic reason is that people - due to the current crises - have lost confidence in institutions and institutional leadership. Institutions are part of the problem and not just the remedy for restoring a sustainable future. If we have to reshape our economic, political, and religious institutions, we need something that has deeper roots than our institutional settings.

Unless leaders in the academic community as well as in corporate, consulting, regulating, and advisory bodies actively focus on motivating and inspiring decision makers to supplement their traditional success criteria with spiritual-based perspectives, business ethics will continue to deal more with non-ethics than with ethics; CSR will continue to emphasize the protection of corporate reputation and success rather than responsibility to broader constituencies; and sustainability will continue to focus on promoting conditions and technologies that enable business growth rather than the maintenance and improvement of the "common good" - including embracing constituencies that lack voice, such as nature and the yet-unborn (Pruzan, 2015a).

There have been significant developments in the broad fields of Business Ethics, CSR, and Sustainability, referred to collectively in the sequel as B-C-S. In the relatively short period of time of roughly 30-40 years, observes Peter Pruzan (2015a, 2015b), all three fields have been characterized by a movement from philosophical reflection and critical perspectives on organized commercial activity, to disciplines characterized by their own vocabularies, measures of performance, university curricula, professional journals, consultancies, nongovernmental organizations, international organizations, and reporting systems.

Some realities, including intangibles such as justice, beauty, serenity, love, and respect, but which do not readily lend themselves to economic measurement, have shown rapid developments from the metaphysical to the physical and from the intrinsic to the extrinsic. Philosophically deep concepts such as ethics, responsibility, and sustainability, each pregnant with significance for reflection on the human condition, have been operationalized and reduced to indicators and variables that can be measured, evaluated, and reported. We should avoid this problem particularly with the concept of spirituality.

Pruzan (2015b) emphasizes the fact that unless a leader's behavior is grounded on existential inquiry that leads to self-knowledge, ethics, no matter how it is taught or what ethical codices are developed to guide behavior in 
organizations, will continue to succumb to the demands of economic rationality. Scandals will continue to anger and frustrate us no matter how much focus our business schools place on business ethics and how many Green Papers are developed to promote corporate social responsibility.

\section{On Corporate Spiritual Leadership}

The evolution of a spiritual-based leadership implies not just a transformation of the teaching and the practice of leadership, but also, and more fundamentally, the transformation of the individual leader's mind-set. What is required is a consciousness that resonates with a conviction that a precondition for the long-term success of purposeful, organized mercantile activity is spiritual-based leadership and not just the pursuit of material gain (Pruzan, 2015b). Scholars and theoreticians must face the challenge of developing vocabularies, perspectives, and research methods that can support leadership that is spiritually based. Instead of a focus on deliberate and willed action that is considered to be the result of logical generalizations and prescriptive principles, this implies a focus on the emancipation and empowerment of inner guidance and embodied knowledge, leading to a shift in consciousness and conscience. Business schools and other institutions of higher learning must face the challenge of integrating spiritual-based leadership in their educational programs without pragmatically reducing it to an instrument of economic rationality - of developing and mediating a leadership paradigm that cannot be taught but which must be accessed via the emancipation of embodied knowledge (Pruzan, 2014).

According to Pruzan (2015a), the concept of spiritual-based leadership is emerging, if not mainstream, as an inclusive and yet highly personal approach to leadership. This concept integrates a leader's inner perspectives on identity, purpose, responsibility, and success with one's decisions and actions in the outer world of business. Spiritual-based leaders are nourished by their spirituality, which is a source within them that informs and guides them. They search for meaning, purpose, and fulfillment in the external world of business and in the internal world of consciousness and conscience. Their external actions and their internal reflections harmonize so that rationality and spirituality are mutually supportive (Pruzan, 2011).

If the business ethics paradigm of moral self-regulation through stakeholder management and CSR programs is not sufficient to overcome the contradictions in our economic system, what can business ethics offer in this context of uncertainty and distrust? Luk Bouckaert (2015, p. 18) responds: we can choose to continue our reformist role within the system as we have done up to now, or we can distance ourselves, apply self-criticism, and try to transform our way of looking at things. The latter route was followed by Socrates in Athens, Lao Tzu in Ancient China, and the Prophets of Israel. Referring to a more recent example, in his Guide for the Perplexed, Ernst Schumacher (1977) also did the same toward the end of his life. In all these writings, we will not find grand theories of leadership and ethics but thoughts about the spiritual way to wisdom, 
leadership, and shared responsibility for the common good. Instead of founding business ethics in the grand rational theories of modernity, such as utilitarianism, Kantianism, and social constructivism, we could find inspiration in the older spirit-driven philosophies of life and community. They can be very helpful with rediscovering the difference between the "ratio" and the spirit as faculties of the human mind. Modern philosophy and education have prioritized human rationality at the cost of spirituality. Along with many others, I believe that it is time to restore the balance between rationality and spirituality and to revitalize our faculty of "spiritual intelligence" as a source of wisdom in management and leadership.

\section{Reflection-based Corporate Spirituality}

The word "reflection" comes from Latin reflectere, meaning to bend back. Reflection implies turning back on oneself to review and assess one's life, actions, and decisions and one's outcomes and achievements. In an organizational context, reflection also means reviewing and learning from an organization's past of deliberations, choices, selections, strategies, implementation, prediction, monitoring, control, and subsequent performance. Boyd and Fales (1983, p. 100) define reflection as "the process of internally examining and exploring an issue of concern, triggered by an experience, which creates and clarifies meaning in terms of self, and which (potentially) results in a changed conceptual perspective." Reflection, accordingly, should lead to new understandings and appreciations (Boud, Keogh, \& Walker,1985). Reflection involves "bending back" upon oneself to take stock, question, and assess one's experiences (Barell, 1995; Moberg, \& Calkins, 2001).

Reflection does not have to be "retrospective" or "self-reflection" as implied by the above definitions. It can be synchronous or contemporary (Schön, 1995) reflecting on current issues of concern, and even "prospective" or anticipatory (Perkins, Jay, \& Tishman,1993). Whether retrospective or introspective or prospective, reflection is interpretative - it reviews and interprets and reinterprets one's experiences with self, organization, or the world of society and environment. Objective and unbiased reflection or self-insight can be positive (Hixon \& Swann, 1993) and can empower one to eliminate some negatives of one's past individual or organizational life such as impulsivity (Wilson et al., 1993), aggressiveness, fraud, corruption, and unethicality (Weick, 1995). However, being a largely personal process, one could also be deluding, self-deceiving, and condoning one's evil past (Kottkamp, 1990, 2000). But when objective, unbiased, and striving for goodness, reflection can be healing, remediating, and help discerning good from bad, fair from unfair, right from wrong practices, or experiences of the past. Sincere reflection can empower us to reorganize our resources and realign our priorities for the future (Shapiro \& Reiff, 1993). Reflection then can be a positive, transforming humanizing, and spiritual experience. 


\section{Is Interfering with Human Nature "Playing God" and Hence Morally Problematic?}

Think of nature rather than what is natural. Trees, grass, birds, forests, animals, mountains, rivers, and the like that we see and enjoy in the countryside are natural; they are not affected by people. Humans, however, are part of nature, part of the natural world just as kangaroos and polar bears are. But are some human interventions such as crops and irrigation, dams and aqua ducts, game hunting and fishing, mining for minerals and clearing forests for road-construction, gardening and landscaping for beauty and building parks for recreation, and the like - are we interfering with nature, and so unnatural? Are we moving into God's domain? Is interfering with nature natural for humans? Are technology and human skills that do it destruction or "enhancement" of nature? Of course, when we overdo it we harm nature ecologically and jeopardize sustainability.

If humans are part of nature, and all other nonhumans are part of the same nature, then what we naturally do is similar: birds build nests while humans build houses; beavers build dams out of trees and sticks, while humans build dams with rocks and concrete. Houses and concrete dams are just as part of nature as nests and beaver dams are (Weckert, 2016, pp. 89-92). However, since humans have free will and autonomy that animals do not have, they have to be responsible for what they do. This is the way we evolved. Kangaroos evolved with strong tails to jump and we evolved as bipedal erect locomotives that enabled our prognathic face to reduce and move backward to make room for the brain to grow with a decision-making capacity that makes us autonomous.

In this sense, humans and nonhumans have no choice but to interfere with nature (or cooperate with nature) in order to survive. However, now that we have earthmoving technologies and human enhancement biotechnologies, our responsibilities increase and need to be reassessed in light of these new situations. In the areas we have control, we have choice, and with choice, responsibility. In the areas we have no control, we have chance, and less responsibility. As Ronald Dworkin (2000, p. 444) wrote: "the crucial boundary between choice and chance is the spine of our ethics and morality, and any serious shift in that boundary is seriously dislocating." In the past, this boundary did not shift dramatically but now it has (Weckert, 2016, p. 94).

Formerly, flooding, droughts, famine, and the like were considered to be acts of God and we could not play God in controlling them. Today, with major dams, we can control all of them to a certain extent - the boundary between choice and chance has changed, and human responsibility is no longer narrowly circumscribed. When boundaries and responsibilities change, decisions and choices must be made in situations where previously none were necessary. The situations of interest are those where no human decision-making was possible but now it is (Weckert, 2016, pp. 94-95).

The current field of geo-engineering and its impact on climate change and its difficulties of gaining international cooperation in dealing with it offers more pertinent examples. Consider solar radiation management also called albedo modification. We are told that by shooting sulfate particles or other chemicals 
into the upper atmosphere to stop some of the sunlight from reaching the earth, the increase in temperature could be slowed, or the temperature held stable or lowered. According to Ken Caldeira, a climate scientist at the Carnegie Institute for Science at Stanford, this is what volcanoes do. He observed that the 1991 Mount Pinatubo volcano in the Philippines spewed lots of small particles high in the atmosphere, and the next year the earth cooled, despite continuous rise in greenhouse gases (Caldeira, 2015). Not only is this process relatively simple, inexpensive, but with quick desirable results. However, tampering with high atmosphere could cause droughts or affect trees and crops causing food shortages or contamination. This is the price of "nature enhancement."

Regarding "human enhancement," we hear about new advances: from organ transplants, we are now moving to body transplants and head transplants (Thomson, 2015). Thus far, we have never been able to choose our bodies. But we have been already modifying our bodies in parts through prostheses, various implants, sex-change, growth hormones, and the like. But changing the whole body (with or without head) to make it stronger, more tanned, more masculine or feminine, a race-change, gender change, species change, and immortality are something new with new alteration or enhancement biotechnologies. Some of these body-transplant interventions can be considered treatments when one's body gets diseased or too old, but most are human enhancements, as the latter change self-identity, self-autonomy, determination, and responsibility. Even if biotechnologies that could make body and head transplants feasible and affordable one day, they raise serious moral problems. They willfully change the boundary between choice and chance, to use Dworkian terms, and our bodies would be matters of choice and not chance or dependent upon God. Given the many unknowns, it is not clear if we have the competence to make good decisions, unless we choose to play God or choose to create a Frankenstein monster. However, as Coady (2009, p. 179) opines, the charge of playing God may be an intrinsic moral objection to the idea of changing human nature.

\section{Ignatian Spirituality: Finding God in All Things}

The Society of Jesus, an organization more than 478 years old, founded by Ignatius of Loyola (1491-1556), whose major work, the Spiritual Exercises (SE), is the foundation for Ignatian or Jesuit Spirituality. Developed after a conversion experience and a long period of renunciation and meditation, the Exercises are a multifaceted, contemplative, personal, and religious activity that is typically conducted over a protracted period of time.

The SE of Ignatius are structured to enable one "to conquer oneself and regulate one's life without determining oneself through any tendency that is disordered" (Fleming, 1991, no. 21). The chief aim of the Exercises is to help the one who does them (traditionally called "the exercitant") attain greater spiritual freedom. They do this by challenging the exercitants to look at their final end (telos) and the behaviors, habits, and values that lead them toward or away from that final good end. In practice, the Exercises are typically undertaken in solitude 
and silence - that is removing oneself or "retreating" from others. The retreatant usually starts meditating on the so-called principle and foundation - an exercise that makes us consider the overall purpose of human existence and the individual's relationship with the transcendent and immanent God. At this point, the exercitant begins to look beyond a narrow self-interested set of desires to the overarching purpose of one's life, being and becoming. The exercitant also begins to scrutinize one's relationship with God and the proper responses to God's creative designs. From the start, the SE encourage purposeful reflection on the relationship between one's everyday activities and the end or set of ends associated with those activities.

One of the fundamental principles of Ignatian spirituality is to "to seek and find God in all things." In Spanish: "La presencia de nuestro Señor en todas las cosas." According to Ignatius, this formula came from God in two ways: (1) through his great and personal mystical life and (2) the Trinity whose vision Ignatius experienced throughout life gave him this formula and confirmed it many times thereafter. Hence, Ignatius expected all his followers to tread the same path of seeking God in all things in order to better serve and love him.

Ignatius made this dynamic formula the central principle of religious and spiritual life, and thereby gave his own order a unique spirituality and the lay people an anxiously awaited method of unifying one's faith with one's everyday living. "If God isn't here, then God isn't anywhere." If God is not present in your day-to-day work and struggle and fun, in your emotions and discoveries, and even in the incidental things that happen, then why should you invest so much time and energy trying to get to whatever place God inhabits? This isn't a form of pantheism - of believing that God is in everything all the time. The idea of finding God in all things points to the love and grace of God that find us no matter what we're going through and no matter what shape we're in.

\section{Concluding Remarks}

"Life is short and we are simply passing through here. We cannot stay. It is therefore essential that we find guides whom we can trust and who can help us discover and realize our higher purposes in life before it is too late. We can channel our deepest creative impulses in loving ways toward fulfilling our higher purposes, and help evolve the world to a better place" (John Mackey, CEO, Whole Foods in Mackey and Sisodia (2014), Conscious Capitalism, p. 7).

We need something that can restore a sense of shared meaning, responsibility, and purpose. This "something" is what we may call spirituality. Spirituality as far as it is defined as an introspective and purely individual search for meaning and happiness may not take us too far. This search of individualized spiritual wellness is fine, but will not suffice as a lever for social and institutional change. That is, we should not reduce spirituality to a hermit's enterprise. As a personal and individual experience, spirituality has the power of reconnecting the self from within to all living beings and to the inner source of life. Because of this capacity of reconnecting people, spirituality has a strong social and public good 
character and is linked with the practice of value-driven leadership and with a deep sense of social responsibility. Without the involvement of intrinsic motivation, corporate ethics may be reduced to being an instrument of reputation and risk management and any genuine moral commitment is lost. Spirituality should therefore be promoted as a public good and a public virtue in any private or public organization. This is spirituality-based leadership with a deep sense of social responsibility.

There is always the risk, however, that this intuitive knowledge will be crowded out by a dominance of rational and pragmatic knowledge that is much focused on problem-solving and controlling our environment. When we observe the wisdom and practice of spiritual-based leaders in history and modern times, we discover that the openness of their minds is always related to a great sensitivity to the vulnerability of life and future generations. Their spirituality is embedded in a deep sense of social responsibility that drives them to action and into being aware of having a historical mission to accomplish. It is this openness of mind, linked to the idea of a historical mission, which forms the motivational and psychological basis for spirituality-based cosmic leadership.

In this book as well as the one that preceded it, we have outlined a journey of ethical, moral, and spiritual corporate executive leadership. The first book described in detail the context of turbulent markets and their challenges that the corporate executives must confront in their day-to-day decisions and strategies. This second book has provided the arsenal of ethical, moral, and spiritual theories, principles, rules, and standards that can inform, form, and transform corporate executive decisions, strategies, and their consequences. Empowered corporate executive ethical life is a lifetime mission, vision, and journey that must be traveled together with others in the organization, with all its stakeholders, with all people, and especially, with close partnership with nature - this is the call of cosmic spirituality and sustainability. 